\title{
The external arguments of weather verbs in Northern Sotho
}

\author{
Mampaka Mojapelo \\ Department of African Languages, Unisa, Box 392, Pretoria, 0003
}

\begin{abstract}
This article investigates the nature and occurrence of external arguments of weather verbs in Northern Sotho, with specific reference to the unaccusative hypothesis. Weather verbs are unaccusative. Their surface structure subject originates as a direct object in the deep structure. Weather verbs tend to select weather nouns as external arguments. They also appear with the null subject meaningfully in a way that no other verb can. Often the external argument and the verb incorporate each other.
\end{abstract}

\section{Introduction}

The aim of this article is to investigate noun phrases (NPs) that may appear as external arguments of weather verbs. Their nature and possible ways in which they may appear in weather verb constructions, as well as their semantic interpretation in the syntactic positions that they occupy will also be examined.

The general framework assumed in this article is the theory of Government and Binding (GB) and the sub-theories that are of particular interest, i.e. Case and Theta theories. Case theory is one of the subtheories of GB-theory that is concerned with ensuring that every overt NP occupies a position which is in certain respects well-formed. Trask (1993) points out that Case theory prevents NPs from appearing in arbitrary positions in which they cannot be suitably interpreted. Case assignment is the assignment of abstract Case to NPs. NPs with phonetic content are required to be case-marked. Case assignment has been formulated in two ways, i.e. Case Filter which applies at the phonetic form (PF) level to exclude NPs which are not case-marked and Visibility Hypothesis which makes case-marking follow from theta-marking, which is obligatory from the Theta Criterion; the NP has to have Case. Case assignment is dependent on government because NPs are assigned Case by their governors. Case assignment has the following principles:

- Nominative Case is assigned by a governing AgrS

- Accusative Case is assigned to objects by transitive verbs (ditransitive verbs assign two instances of accusative case)

- Oblique Case is assigned by Preposition (except locative go)
- Locative Case is assigned by locative preposition go and locative affix -(e)ng

- Genitive Case is assigned by the possessive a

Nominative and Accusative Cases are instances of structural Case assignment; Oblique, Genitive and Locative Cases are instances of inherent Case assignment.

As a requirement of Theta theory a verb or predicate assigns semantic roles to NPs, and they are called theta roles ( $\theta$-roles). Linguistic expressions such as NPs that are assigned $\theta$-roles are called arguments. Trask (op.cit) defines the two types of arguments as follows:

External argument - In GB, an argument of a verb lying outside the subcategorization frame, particularly a subject NP.

Internal argument - an argument of a verb which is located within a verb phrase, such as an object NP.

NPs and clauses which have referential function are potential arguments. Rappaport and Levin (1988) distinguish two lexical representations, i.e. lexical-semantic representation and lexical-syntactic representation. A specific relationship which an argument may bear to its predicate is reflected in the lexical-semantic representation. Jackendoff (1990) developed a theory that refers to lexical-semantic representation as a lexical conceptual structure (LCS). In the lexical-syntactic representation the predicate argument structure (PAS) indicates the number of arguments that a predi- 
cate takes. $\theta$-role assignment must specify in the PAS the variables which are direct, indirect, internal and/or external arguments. According to Rappaport and Levin (op.cit) $\theta$-role assignment can be by a verb, a preposition or a VP via predication. NP arguments are assigned $\theta$-roles differently.

Weather verbs are verbs that denote a weather condition or process. Trask (op.cit) explains a weather verb as a verb which expresses 'a meteorological phenomenon, such as rain, snow, drizzle or freeze'. In the following example sentence, the underlined is a weather verb:

\section{(1) Pula e a sarasara 'Rain drizzles'}

\section{Theoretical Background}

A verb is described as a one-place, two-place or threeplace predicate according to the number of arguments that it takes. Diagrams 1 - 3 are representations of the D-structure based on the VP-internal subject hypothesis, cf. Stroik (2000), Webelhuth (1995) and Pollock in Cowper (1992).

A one-place predicate takes only one argument, i.e. an external argument, as in the following example:

(2a) ..... pudi e hwile

'..... (that) a goat is dead'

(2b) Morphophonological form -hw-

Categorial type

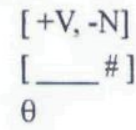

Subcategorial features $\theta$-grid

\section{Diagram 1 One-place predicate}

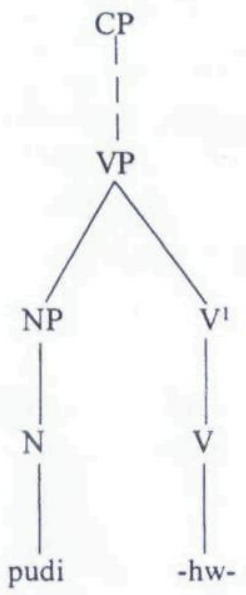

This predicate does not have an internal argument, i.e. there is no object of $\mathbf{- h w}$-.

A two-place predicate takes two arguments, i.e. an external argument and one internal argument, as in the following example:

(3a) .... mma o rata bana

'..... (that) mother loves children'

(3b) Morphophonological form -rat-

$\begin{array}{ll}\text { Categorial type } & {[+\mathrm{V},-\mathrm{N}]} \\ \text { Subcategorial features } & {\left[\_\right.} \\ \theta \text {-grid } & \theta\end{array}$

Diagram 2 Two-place predicate

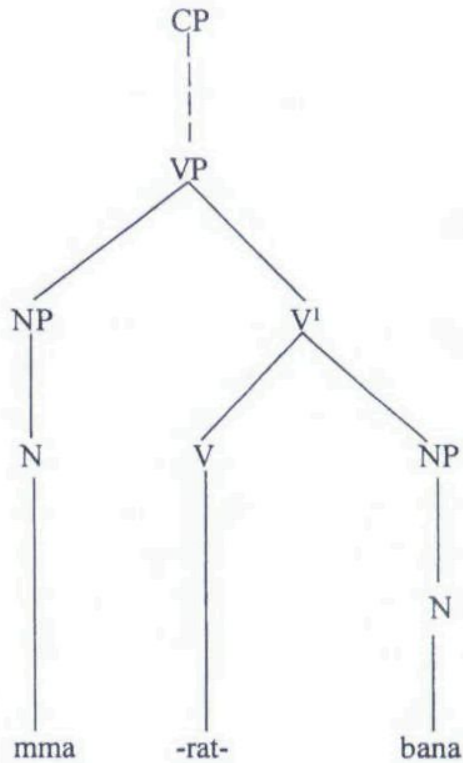

-rat- has one internal argument. Predicates like this one take only one object. They are mono-transitive.

A three-place predicate takes three arguments, i.e. an external argument and two internal arguments, as in the example:

(4a)

$$
\begin{aligned}
& \text {.... Mpho o fa katse meetse } \\
& \text { '.... (that) Mpho gives a cat water' }
\end{aligned}
$$

(4b) Morphophonological form -f-

Categorial type $[+\mathrm{V},-\mathrm{N}]$

Subcategorial features $\theta$-grid 


\section{Diagram 3 Three-place predicate}

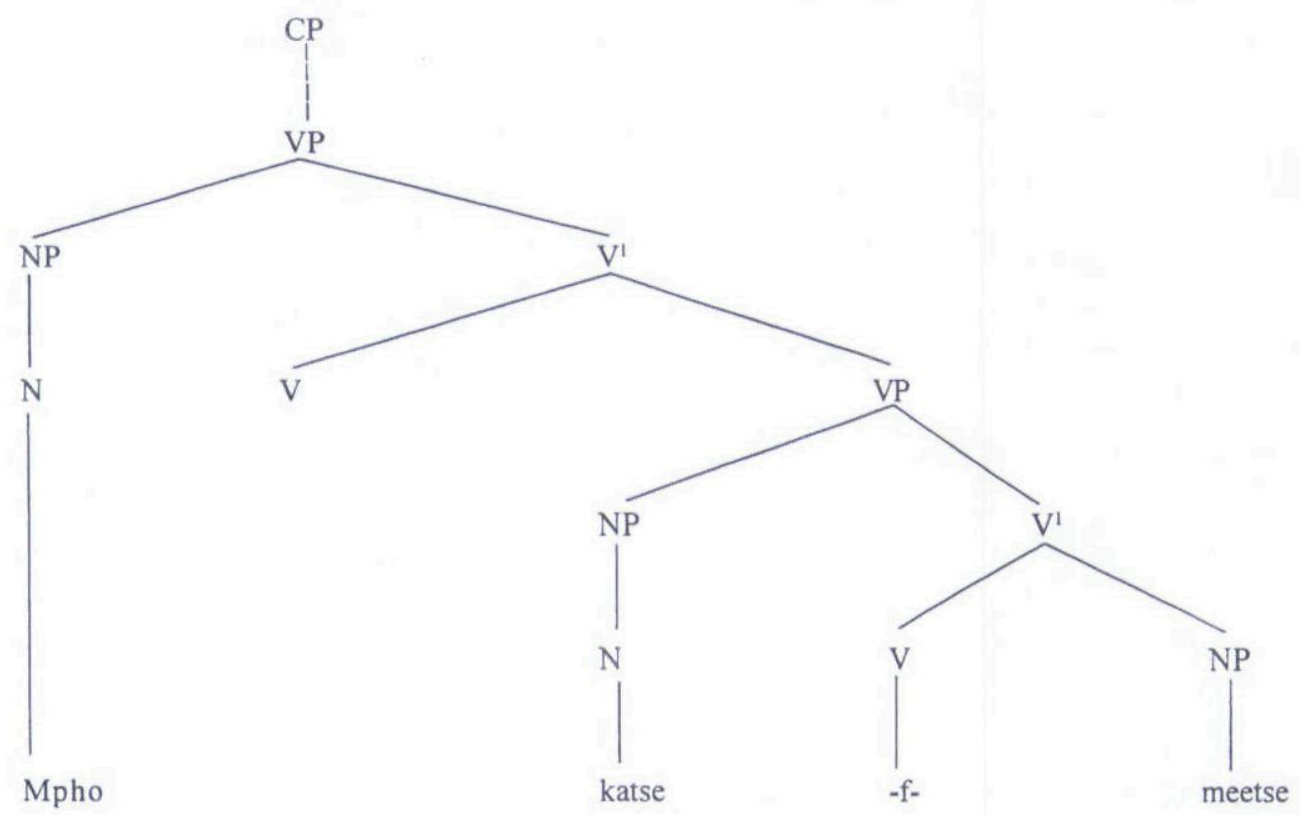

The nature of -f- is such that it should have two objects, a direct and an indirect object.

(3) and (4) illustrate that all internal arguments are within the subcategorization frame of the verb.

Of the three types of predicates above, weather verbs fall under the first. They are intransitive verbs, i.e. they have the same syntactic structure as (2), e.g.

\section{(5a) Phefo e a foka \\ 'Wind blows'}

(5b) Morphophonological form -fok-

$\begin{array}{ll}\text { Categorial type } & {[+\mathrm{V},-\mathrm{N}]} \\ \text { Subcategorial features } & {[} \\ \theta \text {-grid } & \left.{ }{ }^{\#}\right]\end{array}$

Within this type, viz. intransitive verbs, there are semantic classes that display different syntactic behaviours. Weather verbs are unaccusative.

\section{Projection principle and $\theta$-criterion}

The projection principle ensures that a verb may only subcategorize for complements that it $\theta$-marks.

The $\theta$-criterion imposes a one-to-one relation be-

tween $\theta$-roles and arguments. Therefore, each variable in the PAS of -roka (sew) in (6) below must be given an argument:

(6a)

[Mma] o roka [roko]

$\mathbf{X}$

Y

'Mother sews a dress'

(6b)

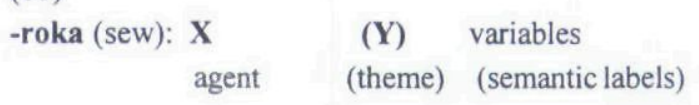

This implies that -roka (sew) has two variables. Thus it assigns two $\theta$-roles, to external $\mathrm{X}$ and to internal argument Y. $\theta$-role assignment gives the association between the NPs in the argument positions of a verb in the syntax and the variables in the PAS of the verb.

\section{Thematic roles}

Because of their nature weather verbs can only assign some of the $\theta$-roles to their arguments. Explanations of the following $\theta$-roles will help in exposing the nature of weather verbs.

Agent is explained by Cowper (1992) as the argu- 
ment that intentionally initiates the action expressed by the predicate. It is, therefore, capable of volition, the intention to act.

\section{(7) [Lehodu] le a utswa \\ 'A thief steals' \\ Lehodu (thief) is agent.}

Theme undergoes the activity that is expressed by the predicate.

\section{(8) [Ledimo] le a tšutla}

'The storm blows aggressively'

Ledimo (storm) is theme.

Patient is affected by the action expressed by the predicate.

(9) [Tate] o tšhogile

'Father is frightened'

Tate (father) is patient.

Location is the place where something is/ happens.

(10) [Mo hlogong] go kolobile

'Here, on the head is wet'

Mo hlogong (here, on the head) is location.

\section{Unaccusative hypothesis}

Intransitive verbs are classified into unergatives and ergatives or, unaccusatives, as suggested by Perlmutter (1978) whose proposal is the first explicit account of the unaccusative hypothesis (UAH). According to Perlmutter unergatives are predicates describing willed or volitional acts, manner of speaking verbs, sounds made by animals and certain involuntary bodily processes. Unergatives have an underlying subject. Unaccusatives on the other hand, are predicates of existing and happening, non-voluntary emission of stimuli that impinge on the senses, aspectual predicates and duratives. Unaccusative verbs have an underlying or initial object.

Trask (1993) explains the concept unaccusative as denoting an intransitive verb or predicate whose NP subject is not an agent or actor, whose surface subject is an underlying (direct) object. To distinguish unaccusatives from unergatives valid diagnostics should be used, taking cognisance of the directness of the relationship between unaccusativity and the grammatical property itself. It needs to be discovered which semantic verb classes act as syntactic unaccusatives and also to find the principles which relate the semantics of the verbs to their syntax.

Grimshaw (1987) and Ruwet (1989), amongst others, studied weather verbs in a number of languages such as French, Italian, English, Greek, German and others and discovered that their syntactic behaviour differs from that of other intransitive verbs. Du Plessis and Visser (1992) are of the view that unaccusative verbs are generally characterised in terms of three properties, i.e. they select an internal argument which is patient or theme, they do not assign an external thetarole, they lack the property of assigning accusative case to the internal argument. This brings us to the question of UAH which is the proposal that unaccusative verbs have an underlying direct object but no underlying subject. Unaccusative verbs include weather verbs.

The following sentence with its derivation illustrates the preceeding situation clearly:

(11a) [Pula] e a khula

'Rain stops raining'

(11b) D- structure: [NP] INFL [ VP -khul- pula] 'stop raining rain'

(11c) S- structure: [NPpula $]$ INFL [ VP - khul-t t $_{i}$ ] 'rain stops raining'

NPpula (rain) originated as a direct object of -khula (stop raining) with a thematic role of theme. As a requirement of Case filter it has to move to the subject position where it will receive nominative case through agreement of inflection. This is the case because -khula (stop raining) is intransitive; as a result it does not have accusative case assigning property. This case is similar to that of the passive verb. 


\section{The predicate argument structure of weather verbs}

As intransitives, weather verbs are one-place predicates. The lexical entry of a verb stem such as -hlafile (rough) as in

\section{(12a) [Legodimo] le hlafile 'the sky is rough/bad'}

would be:

(12b) Morphophonological form

$$
\begin{aligned}
& \text { Categorial type } \\
& \text { Subcategorial feature }
\end{aligned}
$$$$
\theta \text {-grid }
$$

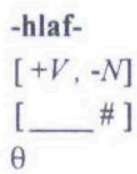

The subcategorial feature shows that there is no complement of -hlaf-. Legodimo is an external argument and it is assigned a thematic role of theme, i.e. NPlegodimo (sky) is undergoing the action/ process expressed by the predicate.

To find out which external arguments may appear with weather verbs, the possible ways in which they may appear with weather verbs and the interpretation of those arguments in their positions we shall use a few examples with literal translations, as far as possible, in each instance in order to expose the syntactic behaviour of the verbs and their arguments. NP (weather nouns and non-weather nouns), Empty categories and Locatives as external arguments of weather verbs shall be investigated.

\section{NP as external argument of weather verbs}

\section{Weather nouns}

Pula (rain) may be used as an example of weather nouns that appear as external arguments of weather verbs. As a weather NP it may appear with a number of weather verbs as in the following examples:
(13) [Pula] e a rotha
'Rain drips'
(14) [Pula] e a sarasara
'Rain drizzles'

(15) [Pula] e a gaotša

'Rain pauses'

(16) [Pula] e a khula

'Rain stops raining'

(17) [Pula] e a na

'Rain rains'

(18) [Pula] e a duma

'Rain thunders'

(19) [Pula] e a tšhologa

'Rain pours'

(20) [Pula] e a gadima

'Rain flashes'

In example sentences (13)-(20) above pula (rain) is external argument with thematic role of theme.

Other weather NPs may be used in descriptive possessive constructions with pula (rain) where the whole NP is external argument of a weather verb.

(21) [Pula ya modupi] e a na

'Rain -of soft continuous rain- rains'

In (21) above the NP which appears in the descriptive possessive construction as complement of the possessive a may be taken out to appear without pula (rain) as subject of the weather verb as in:

(22) [Modupi] o a na

'Soft continuous rain rains'

It may not be possible for the descriptive NP to appear after the weather verb as a cognate object. A construction like:

\section{(23) *[Pula] e na [modupi]}

'Rain rains soft continuous rain'

is ungrammatical in Northern Sotho.

The descriptive NP, however, may occur in a prepositional phrase as complement of ka: 
(24a) [Pula] e na [ka modupi]

'Rain rains -in the form of- soft continuous rain'

A verse from the hymn in Difela tsa Sione, has the lines:

(24b) Pula tsa lehlohonolo,

Ha li na ka medupe

'Rains of luck, when they rain - in the form of soft continuous rain'

Another similar construction, abstracted from a traditional wedding song:

(24c) Dipula di ka na ka matlorotloro X 3

'Nar'o tšea ngwetši -

'Rains may rain in torrents, we are going to take the bride'

i.e., no matter how bad the weather may be we are determined and we will go and bring the bride home.

The interpretation of ka modupi, ka medupe and ka matlorotloro in (24) above is that of manner.

The same exercise may be done with descriptive NPs like mosarasarana (drizzle), sefako (hail), magadima (lightnings), matlakadibe (thunderstorms), etc.

The interpretation of ka sefako would be that of accompaniment:

(25) [Pula] e na [ka sefako]

'Rain rains - together with - hail'

Similar semantic interpretation of ka can be illustrated as follows, with non-weather verbs:

(26a) Ke nwa teye ka borotho

'I drink tea - together with/accompanied by bread'

(26b) Ngwetši e ya kgonyeng ka ngwana

'The daughter-in-law goes to collect fire-wood

- together with/accompanied

by - the baby, i.e. with the baby on her back'
These examples in which there is nothing instrumental about ka are just a few to demonstrate the many semantic functions of ka in Northern Sotho.

In Northern Sotho, weather verbs and weather nouns often make exclusive selection of one another, and may not always be used in descriptive possessive constructions.

Naka (a star that appears at the commencement of winter - symbolic of very cold weather) is an example of such weather nouns. Naka (winter star) may be descriptive of marega (winter) and phefo (wind/cold weather) but it may not appear in a descriptive possessive construction with any of these NPs.

Whilst we have:

(27) [Marega] a a tonya

'Winter is cold'

(28) [Phefo] e a foka/tonya

'Wind blows/ is cold'

we cannot have:

(29) [*Phefo ya naka] e a tonya

"Wind 'of winter star' is cold", for instance.

NPnaka (winter star) may only appear alone as subject and it selects weather verbs -tšhuma (burn) and -raga (kick) as in:

(30) [Naka] e tšhumile

'Winter star has burnt'

(31) [Naka] e ragile

'Winter star has kicked'

Both (30) and (31) are descriptive of extremely cold conditions that prevail when the winter star has appeared; cases where green plants turn brown.

Weather verbs, therefore, make a selection of which NPs they'd like to appear with, and how they'd be used in those combinations for specific weather conditions. 


\section{Non-weather nouns}

The following are examples of non-weather nouns that may appear as external arguments of weather verbs and their thematic roles.

Inanimate

(32) [Ntwa] e a fiša

'The war/fight is hot'

(33) [Moriti] o a tonya

'The shade is cold'

(34) [Meriti] e a fiša

'Shadows are hot' - a matter of cultural impurity

(35) [Ntlo] e ruthetše

'The house is warm'

(36) [Ntlo] e a na

'The house rains'

NPs ntwa (war), moriti (shade), meriti (shadows), and ntlo (house) in (32) - (35) above, appear with temperature weather verbs and they are all assigned thematic role of patient. Example (36) is an exception in that the VP is a non-temperature weather verb and the NP is assigned thematic role of theme. The house does not actually 'rain'. The condition of the roof is such that rain water comes from the roof in a similar way that it comes from the sky when it rains. NP ntlo (house) in (36), as a result, acquires a secondary role. Other weather verbs that denote various intensities of -na (rain) may also be used in the same context e.g. -rotha (drip) and -korotla (rain heavily).

\section{Animate}

(37) [Molwetši] o a fiša

'A sick person is hot' - feverish

(38) [Setopo] se a tonya

'A corpse is cold'
Body parts:

(39) [Mafahla] a a fiša

'The chest is hot'

(40) [Diatla] di omile

'Hands are dry' - extremely cold

In example sentences (37) - (40) above the NPs are assigned thematic role of patient and they all appear with temperature weather verbs.

We may, therefore, conclude that when nonweather nouns, both animate and inanimate - concrete and abstract, appear as external argument of weather verbs they seem to appear only with temperature weather verbs and they are assigned thematic role of patient. (36) is an exception and the semantics thereof has already been explained.

\section{Empty categories}

If no noun belonging to a noun gender class occurs as subject or object, 'small' pro appears and is co-indexed with agreement of inflection. We shall only concern ourselves with the empty NP subject because weather verbs are one-place predicates. In the languages studied by Ruwet (1986), he found that weather verbs behave differently from other intransitive verbs in the way they appear with the null or impersonal subject. In examining the distribution of this null or impersonal subject, Ruwet finds that it does not appear meaningfully with other intransitive verbs as it does with weather verbs.

\section{Small pro}

Let us contrast the Northern Sotho intransitive verbs -lla (cry) (non-weather verb) and -na (rain) (weather verb):

\section{(41a) [Pudi] e a lla}

'The goat cries' - bleats

(41b) [pro] e a lla

'It cries' 
(42a) [Pula] e a na

'Rain rains'

(42b) [pro] e a na 'It rains'

Sentence (41b) above may only be understood in context because pudi (goat) is not the only (or the main) external argument that may be subcategorized by the verb -lla (cry). There are a lot of things that a goat may do except crying, it does not depend on crying for its existence. VP-Ila (cry), also, can have a lot more NPs as external arguments like:

(43) [Ngwana] o a lla

'A child cries'

(44) [Moropa] o a lla

'A drum cries' - sound when beaten

(45) [Seyalemoya] se a lla

'A radio cries' - is on

(46) [Phalafala] e a lla

'A horn cries' - sound when blown

On the contrary, some weather nouns may be left out without giving any context and empty pro with AgrS may suffice as subject as in example (42b) above. VP-na and NPpula appear to incorporate each other semantically. The one cannot exist without the other. The two depend on each other for their existence. Other examples are:

(47) [pro] e a sarasara

'It drizzles'

(48) [pro] le hlakile

'It is ready' - just about to rain

(49) [pro] e a foka

'It blows'

This is characteristic of weather verbs. The event presents itself in such a way that it becomes extremely difficult to differentiate the action from that to which it happens. When observing the phenomena it is not easy, if at all possible, to distinguish pula (rain) from -na (rain) or phefo (wind) from -foka (blow). The two are intertwined.

Other weather nouns, however, are necessary as subjects of weather verbs - this is due to the fact that the weather verbs concerned may subcategorize other NPs as well. The verb as such does not have enough reference to include the weather noun. Examples are:

(50a) [Phoka] e wele 'Dew fell'

(50b) [pro] e wele 'It fell'

(51a) [Sefako] se a tologa 'Hail thaws'

(51b) [pro] se a tologa 'It thaws'

(52a) [Letšatši] le a hwa 'The sun dies' - eclipse

(52b) [pro] le a hwa 'It dies'

If empty pro appears as subject as in (50b), (51b) and $(52 \mathrm{~b})$ above, the sentence will be unclear unless it appears in a specific weather context.

This meaning reflection of co-existence of VP and NP, as illustrated in (42), (47), (48) \& (49) seems to happen only with weather verbs.

\section{Agreement morpheme go}

Agreement morpheme go may appear as subject with empty pro with some weather verbs, where it has no reference to any lexical NP. This agreement morpheme go coindexed with pro is assigned a $\theta$-role of quasiargument - it does not have the referential function that other arguments such as letšatši (sun) or sefako (hail) have, yet it is a thematic subject of a weather 
verb. The following are examples of go with pro as external argument of weather verbs:

(53) Go a tonya

'It is cold'

(54) Go a apoga

'It clears away'

(55) Gofodile

'It is cool'

(56) Go a fifala

'It darkens'

\section{Locatives}

Locative nouns (classes 16-18 plus a few more in classes $5,9 \& 14$ ), those that are marked by the locative suffix -(e)ng, those that are marked by ' $g o$ ' and ' $g a$ ' as well as names of places may appear as external arguments of weather verbs. Examples are:

(57) [Godimo] go a tonya 'Up is cold'

(58) [Moeding] go ruthetše 'In the valley is warm'

(59) [Moseo] go a rotha 'At the far back - in the house - is dripping'

(60) [Kua dithabeng] go a gadima 'There at the mountains is flashing'

NPloc can appear as subject with non-temperature and temperature weather verbs. By virtue of being NPloc it is assigned $\theta$ role of location.

\section{Conclusion}

This article presented a reflection on the syntactic appearance of weather verbs in their basic form, as well as the semantics thereof. Weather verbs take mainly weather nouns as external arguments with a thematic role of theme. The external argument of a weather verb cannot be an agent. Even though they are intransitive, weather verbs display syntactic behaviour that is different from other intransitive verbs. When non-weather nouns, both animate and inanimate - concrete and abstract, appear as external arguments of weather verbs they appear only with temperature weather verbs, and they are assigned thematic role of patient. Because of its nature NPloc is assigned thematic role of location. Small pro can be used meaningfully with weather verbs, without assistance of context, in a way that other verbs can't. A weather verb selects an external argument and channels its semantic interpretation to suit its nature.

\section{References}

Cowper, E. 1992. A concise introduction to syntactic theory. London: University of Chicago.

Du Plessis, J.A. \& Visser, M.W. 1992. Xhosa syntax. Pretoria: Via Afrika.

Grimshaw, J. 1987. Unaccusative - an overview. In Proceedings of NELS 17, 244-59. GLSA, University of Massachusetts. Amherst.

Jackendoff, R. 1990. Semantic structures. Cambridge Massachusetts: MIT Press.

Perlmutter, D. 1978. Impersonal passives and the unaccusative hypothesis. Proceedings of the Berkeley Linguistic Society 4:157-189.

Rappaport, M. \& Levin, B. 1988. What to do with eroles. W. Wilkins (ed.) Syntax and Semantics 21. San Diego: Academic Press.

Ruwet, N. 1986a. On weather verbs. CLS 22 Part 1. Chicago Linguistic Society, pp. 195-215. Université de Paris and University of Chicago.

Ruwet, N. 1986b. Weather verbs and the unaccusative hypothesis. Université de Paris.

Stroik, T. 2000. Syntactic controversies. Muenchen: Lincom Europa.

Trask, R.L. 1993. A dictionary of grammatical terms in linguistics. London: Routledge.

Webelhuth, G. 1995. Government and binding theory and the minimalist program. Oxford: Blackwell. 
Copyright of South African Journal of African Languages is the property of University of Port Elizabeth, Department of African Languages and its content may not be copied or emailed to multiple sites or posted to a listserv without the copyright holder's express written permission. However, users may print, download, or email articles for individual use. 